\title{
VULCANISMO BASÁLTICO DE AFINIDADE SHOSHONÍTICA EM AMBIENTE DE ARCO ARQUEANO, GRUPO GRÃO-PARÁ, SERRA DOS CARAJÁS - PARÁ
}

\author{
MARCELO R. MEIRELLES* e MARCEL A. DARDENNE*
}

\begin{abstract}
BASALTIC VULCANISM OF SHOSHONITIC AFINITY IN ARCHEAN ARC ENVIRONMENT, GRÃO-PARÁ GROUP, SERRA DOS CARAJÁS - PARÁ. The N4 and N8 orebodies in the Carajás district are associated to the Archean volcano-sedimentary Grão-Pará Group. The volcanic portion of this group comprises mainly basalts and basaltic andesites with local basic to intermediate pyroclastic intercalations. Associated intrusive bodies occur locally. Volcanic rocks were extruded in a subaqueous environment and submitted to hidrothermal metamorphic event of the greenschist facies. The absence of penetrative structures and the conspicuous occurrence of several primary textures are important features of the volcanic rocks associated to the orebodies. Geochemically the metabasic rocks are characterized by high contents of $\mathrm{K}, \mathrm{Ba}$ and $\mathrm{Rb}$, and low $\mathrm{Zr}, \mathrm{Nb}$ and $\mathrm{Ti}$, typical of the shoshonitic series. Petrologically the basic rocks of the Grão-Pará Group indicate a subduction zone geotectonic environment.
\end{abstract}

Keywords: Basaltic vulcanism, Serra dos Carajás.

\begin{abstract}
RESUMO Os corpos N4 e N8, pertencentes ao Distrito Ferrifero de Carajás, são constituídos por uma associação vulcanossedimentar arqueana do Grupo Grão-Pará. O pacote vulcânico, apresentando níveis intrusivos, é composto essencialmente por basaltos e andesitos basálticos, com contribuições locais de rochas piroclásticas de natureza básica e intermediária. Tais rochas foram formadas em ambiente subaquoso e submetidas a metamorfismo hidrotermal de fácies xisto-verde. A ausência de estruturas penetrativas e a preservação de inúmeras feições primárias, são aspectos marcantes da associação vulcanossedimentar dos corpos N4 e N8. Geoquimicamente, as rochas metabásicas são caracterizadas por altos teores de $\mathrm{K}, \mathrm{Ba}$ e $\mathrm{Rb}$, associados a baixos teores de $\mathrm{Zr}$, $\mathrm{Nb}$ e $\mathrm{Ti}$, o que permite incluí-las na série shoshonítica. Do ponto de vista geotectônico, as rochas básicas do Grupo Grão-Papá sugerem um ambiente de arco magmático para sua origem.
\end{abstract}

Palavras-chaves: Vulcanismo basáltico, Serra dos Carajás.

INTRODUÇÃO Este trabalho, que representa parte do tema de dissertação de mestrado desenvolvido por Meirelles (1986) no Departamento de Geociências da Universidade de Brasília, pretende, por meio do estudo geoquímico e petrológico das rochas vulcânicas do Grupo Grão-Pará na Província de Carajás, contribuir para uma melhor caracterização do vulcanismo associado aos jaspilitos e, em conseqüência, para uma definição mais adequada do quadro geotectônico da região.

GEOLOGIA REGIONAL As principais unidades litoestratigráficas da Província de Carajás (Fig. 1) foram revisadas por Hirata et al. (1982) e por Meireles et al. (1984). Segundo esses autores, os terrenos mais antigos correspondem a uma associação granito-greenstone de idade arqueana, denominada de Complexo Xingu (Silva et al. 1974). Este complexo compreende rochas polimetamórficas de alto grau (gnaisses, anfibolitos e migmatitos), além de granitos e cataclasitos, que envolvem seqüências vulcano-sedimentares do tipo Greenstone Belts (Andorinhas, Gradaús, Sapucaia e Rio Novo), além de complexos básico-ultrabásicos.

A seqüência Salobo-Pojuca, constituída por uma associação vulcanossedimentar metamorfisada em médio e alto grau, apresenta importantes depósitos sulfetados de $\mathrm{Cu}-\mathrm{Au}$ (Farias et al. 1984).

O Grupo Grão-Pará, que contém o enorme depósito de ferro da Serra dos Carajás, é representado por uma espessa seqüência vulcânica na qual se intercalam os jaspilitos (Beisiegel et al. 1973). Esta seqüência foi datada em 2,7 Ga pelo método U-Pb por Wirth et al (1986).

A seqüência vulcanossedimentar do "Prospecto Bahia" é composta por derrames e sills básicos, tufos intermediários a ácidos, sedimentos elásticos, formações ferríferas bandadas e mineralizações de cobre (Ferreira 1985). Segundo este autor, a datação Rb-Sr sobre granófiros básicos fornece uma idade de 2,6 Ga (Ferreira \& Danni 1985).

As seqüências sedimentares elásticas que recobrem discordantemente as unidades precedentes são correlacionadas à Formação Rio Fresco por Barbosa et al. (1966). São formadas por sedimentos elásticos grossos na base, passando para sedimentos finos no topo, com contribuições químicas locais (Meireles et al 1984).

Corpos graníticos são freqüentes na Província de Carajás. Os mais antigos, de idade arqueana, são associados com as seqüências do tipo greenstone belt. Os mais jovens são intrusivos nas rochas vulcânicas do Grupo Uatumã, com idades em volta de 1,6 Ga. Na área, o Granito Carajás, que é intrusivo no Grupo Grão-Pará e na Formação Rio Fresco, mostrou idade de 1,8 Ga pelos métodos Rb-Sr e U-Pb (Wirth et al 1986, Gibbs et al 1986).

SEQÜENNCIA VULCANOSSEDIMENTAR DO GRUPO GRÂO-PARÁ A seqüência vulcanossedimentar do Grupo Grão-Pará é composta pelas seguintes unidades (Beisiegel et al 1973): vulcânicas máficas (unidade inferior), jaspilitos (unidade intermediária) e vulcânicas máficas (unidade superior). Essas unidades são bem representadas em sondagem nos corpos N4 e N8, permitindo uma ampla amostragem de rochas vulcânicasjfrescas pertencentes as unidades vulcânicas inferior e superior. Cabe ressaltar que a denominação unidade "inferior" ou "superior" se refere à posição estrutural das rochas vulcânicas em relação aos jaspilitos, não possuindo valor estratigráfico: 

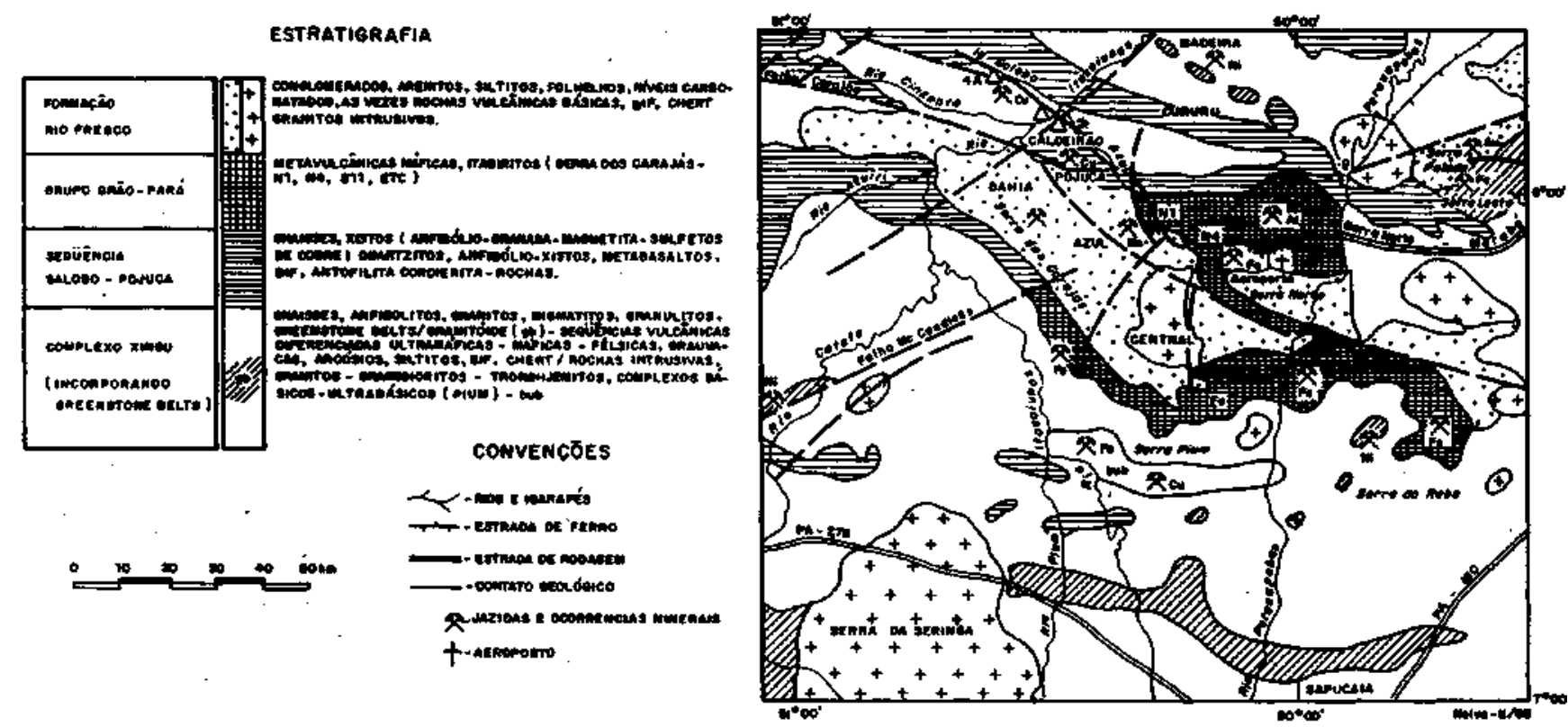

Figura 1 - Mapa Geológico da Província Mineral de Carajás (segundo Hirata et al. 7982, simplificado) Figure 1 - Geological map of the Carajás Province (after Hirata et al. 1982, modified)

a. Unidade inferior: é constituída predominantemente por basaltos e andesitos basálticos, com contribuições piroclásticas de natureza básica a intermediária. Todas as rochas desta unidade foram submetidas a metamorfismo hidrotermal de intensidade variável.

b. Unidade intermediária: possui caráter essencialmente sedimentar. É representada por jaspilitos que recobrem a unidade anterior. No local, foi constatada uma intercalação de rocha vulcânica de natureza intermediária ou ácida, bastante alterada.

c. Unidade superior: encontra-se estruturalmente acima dos jaspilitos. É formada por rochas vulcânicas máficas (basaltos) e sills de rochas intrusivas (andesitos basálticos), que são hidrotermalmente alterados.

d. Unidade elástica: nesta seqüência, foram observados quartzo-arenitos e níveis de conglomerados com seixos arredondados e angulosos de quartzitos, jaspilitos e vulcânicas máficas.

PETROGRAFIA DAS ROCHAS METAMÁFICAS Sob esta denominação estão incluídos os derrames de basaltos amigdaloidais e andesitos basálticos, bem como rochas intrusivas na forma de diques ou sills. Âs rochas vulcânicas são geralmente maciças, freqüentemente amigdaloidais (Foto 1, Prancha 1) e apresentam texturas diversas: intergranular, subofitica (Foto 2, Prancha 1), quench (Foto 3, Prancha 1) e glomeroporfirítica. É comum a presença de fenocristais de plagioclásio e, localmente, de augita. Ass rochas de granulometria mais grossa, com texturas subofíticas e ricas em intercrescimentos granofíricos, sem evidências de estruturas amigdaloidais, foram interpretadas como corpos intrusivos. Nessas rochas subvulcânicas, foram identificados cristais de ortoclásio (Foto 4, Prancha 1). A abundância dos intercrescimentos granofiricos (geralmente $15 \%$ em volume) e a presença de feldspato potássico parecem indicar magma original rico em potássio, rubídio e bário. Segundo Joplin et al. (1972), o material intersticial mais importante das séries shoshoníticas é o feldspato potássico.

A mineralogia das rochas básicas consiste principalmente de clorita, augita, actinolita, plagioclásio sódico parcialmente alterado e, subordinadamente, quartzo, carbonato, titanita, leucoxênio, magnetita, epídoto e feldspato potássico.
PETROGRAFIA DAS ROCHAS METAPIROCLÁSTI-

CAS Dois níveis pouco espessos $(1 \mathrm{~m})$ de rochas metapiroclásticas foram observados nas proximidades do contato unidade vulcânica inferior/jaspilitos. Os tufos líticos, de composição intermediária, mostram clastos líticos e fragmentos de púmice (Foto 5) sustentados por matriz constituída principalmente por uma associação silicosa de granulometria muito fina. Apresentam ainda abundantes shards (Foto 6). Os tufos finos, de composição básica, caracterizam-se pela presença de litoclastos e cristaloclastos imersos numa matriz muito una composta por clorita, feldspato, quartzo, epídoto e leucoxênio.

As principais feições petrográficas das rochas vulcânicas e subvulcânicas dos corpos N4 e N8, consistentes com a presença de metamorfismo hidrotermal, são:

- presença de clinopiroxênio ígneo junto com uma associação mineralógica de baixa temperatura;

- substituição pseudomórfica preservando a textura ígnea primária;

- desenvolvimento de minerais secundários sem xistosidade; - as diversas transformações mineralógicas foram condicionadas pelas anisotropias e permeabilidades do material basáltico, e os maiores reajustes ocorreram na porção superior dos derrames máficos, particularmente nas zonas apresentando alta densidade de vesículas.

Os estudos sobre a alteração hidrotermal envolvendo processo de espilitização desenvolvidos por Meirelles (1986) permitiram estabelecer a seguinte escala de mobilidade relativa para os elementos maiores e traços:

- mobilidade alta: Mn, Na, Ca, Zn, Cu, Ba e Sr;

- mobilidade moderada: Fe, K, Mg, Cr, Pb e Rb;

- imobilidade relativa: P, Ni, Zr, V, Ti, Y e ETR.

CARACTERIZAÇÃO GEOQUÍMICA E GEOTECTÔNICA DO VULCANISMO SHOSHONÍTICO A gênese das rochas vulcânicas de afinidade shoshonítica tem sido atribuída a processos associados a zonas de convergência de placas (arcos de ilhas, exemplo, Fiji; margens continentais ativas, exemplo, Andes Central; e zonas de colisão continental, exemplo, Irã) e com ambientes não diretamente relacionados com o processo de subducção, isto é, rochas geradas após o término da subducção, como em New South Wales, Austrália (Carr \& Fardy 1983). Os shoshonitos são ligados às fases 

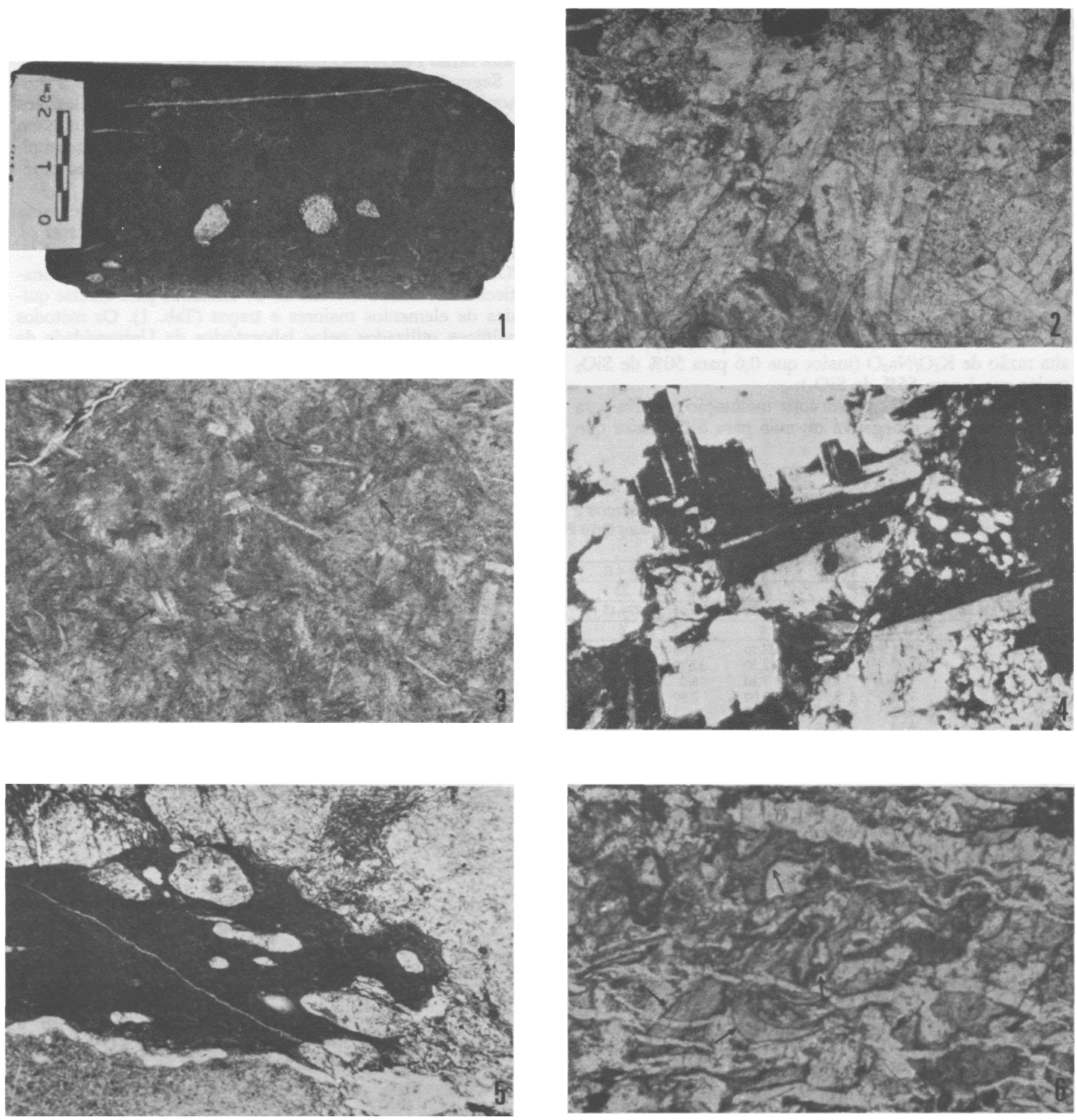

Prancha 1-1. Grandes amígdalas preenchidas por calcita e clorita; 2. Fotomicrografia de textura subofitica reliquiar. As ripas de plagioclásio encontram-se parcialmente inclusas nos minerais ferro-magnesianos (mistura de actinolita e clorita). N//. Escala: $1 \mathrm{~cm}$ na foto corresponde a 0,25 mm; 3. Fotomicrografia de textura quenching, cujas feições refletem condições muito rápidas de cristalização do magma. Os cristais "quench" do piroxênio original (atualmente pseudomorfisado por actinolita) formam agregados tipo feixe, enquanto os cristais "quench" de plagiclásio mostram as características típicas desta textura, isto é, hábito esqueletal e tipo rabo de andorinha*. Localmente, são vistas seções ocas* destes cristais. N//. * $\uparrow$. Escala: $1 \mathrm{~cm}$ na foto corresponde a 0,19 mm; 4. Fotomicrografia de cristais de ortoclásio com geminação carlsbad sendo substituídos por microclínio. Rocha metabásica intrusiva. NX. Escala: $1 \mathrm{~cm}$ na foto corresponde a 0,21 mm; 5. Fotomicrografia de fragmento depúmice achatado em forma de labaredas (Fiamme). Localmente, são preservadas grandes cavidades vesiculares (atualmente constituídas por quartzo) formadas pelo escape e concentração de fluidos. Tufo lítico. NX. Escala: 1 cm na foto corresponde a $0,55 \mathrm{~mm}$; 6. Fotomicrografia de diversos shards* (fragmentos vítricos de paredes de bolhas rompidas pela atividade vulcânica explosiva) pseudomorfisados por material criptocristalino, mostrando contorno sinuoso e em forma de cúspide. Tufo lítico. N//. * $\uparrow$. Escala: $1 \mathrm{~cm}$ na foto corresponde a $0,09 \mathrm{~mm}$

Plate 1-1. Large amygdals filled with calcite and chlorite; 2. Subophitic relict texture. NPL. Scale: $1 \mathrm{~cm}$ on the photograph is equal to $0,25 \mathrm{~mm} ; 3$. Quenching texture. NPL. Scale: $1 \mathrm{~cm}$ on the photograph is equal to $0,19 \mathrm{~mm}$; 4 . Orthoclase crystals with carlsbad gemination substituted by microcline (Metabasic intrusive). PL. Scale: $1 \mathrm{~cm}$ on the photograph is equal to $0,21 \mathrm{~mm} ; \mathbf{5}$. Fiamme texture (Lithic tuff). PL. Scale: $1 \mathrm{~cm}$ on the photograph is equal to $045 \mathrm{~mm} ; \mathbf{6}$. Shards (Lithic Tuff). NPL. Scale: $1 \mathrm{~cm}$ on the photograph is equal to $0,09 \mathrm{~mm}$ 
tardias do processo de subducção com freqüente desenvolvimento de magmatismo alcalino após a estabilização do arco (Morrison 1980, Venturelli et al 1984, Ujike 1985).

Autores como Joplin et al (1972) relacionam as rochas shoshoníticas à série cálcio-alcalina, enquanto Dickinson et al (1968), Gill (1970) e Windley (1984) consideram estas rochas como equivalentes às séries alcalinas. Entretanto, uma revisão das diversas associações shoshoníticas sugere para este grupo de rochas ricas em $\mathrm{K}$, com afinidades cálcio-alcalinas, uma série independente (Mackenzie \& Chappel 1972, Morrison. 1980, Hughes 1982).

Morrison (1980), com base em inúmeras ocorrências selecionadas da literatura, faz um resumo das principais características químicas da série shoshonítica:

- basaltos aproximadamente saturados em sílica;

- baixo enriquecimento em ferro;

- alto teor de alcalis $\left(\mathrm{Na}_{2} \mathrm{O}+\mathrm{K}_{2} \mathrm{O}\right.$ maior que 5\%);

- alta razão de $\mathrm{K}_{2} \mathrm{O} / \mathrm{Na}_{2} \mathrm{O}$ (maior que 0,6 para $50 \%$ de $\mathrm{SiO}_{2}$ e maior que 1 para $55 \%$ de $\mathrm{SiQ}_{2}$ );

- o diagrama $\mathrm{K}_{2} \mathrm{O}-\mathrm{SiO}_{2}$ mostra forte inclinação positiva para $45 \%-57 \%$ de $\mathrm{SiO}_{2}$ e negativa ou nula para $\mathrm{SiO}_{2}$ maior que $57 \%$;
- enriquecimento em $\mathrm{P}, \mathrm{Rb}, \mathrm{Sr}, \mathrm{Ba}$ e terras raras leves;

- baixo teor de $\mathrm{TiO}_{2}$ (menor que 1,3\%);

- conteúdo elevado, porém variado, de $\mathrm{A}_{2} \mathrm{O}_{3}$ (14\%-19\%);

- alta razão $\mathrm{Fe}_{2} \mathrm{O}_{3} / \mathrm{FeO}$ (maior que 0,5\%).

Segundo Pearce (1982), as rochas cálcio-alcalinas e shoshoníticas são enriquecidas em elementos alcalinos e alcalinos terrosos, além de $\mathrm{Th}, \mathrm{Ce}, \mathrm{P}$ e $\mathrm{Sm}$, mostrando, entretanto, um empobrecimento em $\mathrm{Ta}, \mathrm{Nb}, \mathrm{Zr}$, Hf, Y e $\mathrm{Yb}$, elementos tipicamente enriquecidos em rochas vulcânicas alcalinas intraplacas (Ujike 1985).

Rochas vulcânicas arqueanas formadas em ambiente de arco magmático maturo foram descritas por Brooks et al (1982) e Ujike (1985).

CONSIDERAÇÕES PETROGENÉTICAS Métodos analíticos Foram selecionadas 27 amostras para análise química de elementos maiores e traços (Tab. 1). Os métodos analíticos utilizados pelos laboratórios da Universidade de Brasília - UnB e GEOSOL para dosagem dos elementos foram os seguintes: $\mathrm{TiO}_{2}, \mathrm{~V}, \mathrm{Sr}, \mathrm{Y}, \mathrm{Zr}, \mathrm{Nb}, \mathrm{Ba}$ e ETR - espectometria de plasma; $\mathrm{Rb}, \mathrm{Nb}$ e $\mathrm{SO}_{2}$ - fluorescência de raios $\mathrm{X} ; \mathrm{SiO}_{2}$, $\mathrm{A}_{2} \mathrm{O}_{3}, \mathrm{TiO}_{2}$ e $\mathrm{P}_{2} \mathrm{O}_{5}$ - espectrofotometria absoluta; $\mathrm{FeO}, \mathrm{MgO}$ e $\mathrm{CaO}$ - volumetria; $\mathrm{Fe}_{2} \mathrm{O}_{3}, \mathrm{MnO}, \mathrm{Ni}, \mathrm{Cr}, \mathrm{Cu}, \mathrm{Pb}, \mathrm{Zn}$ e $\mathrm{Co}-$

Tabela 1 - Análises químicas de elementos maiores, traços e terras raras de rochas vulcânicas do Grupo Grão-Pará Table I - Chemical analyses of major, trace and REE elements from Grão-Pará volcanic rocks

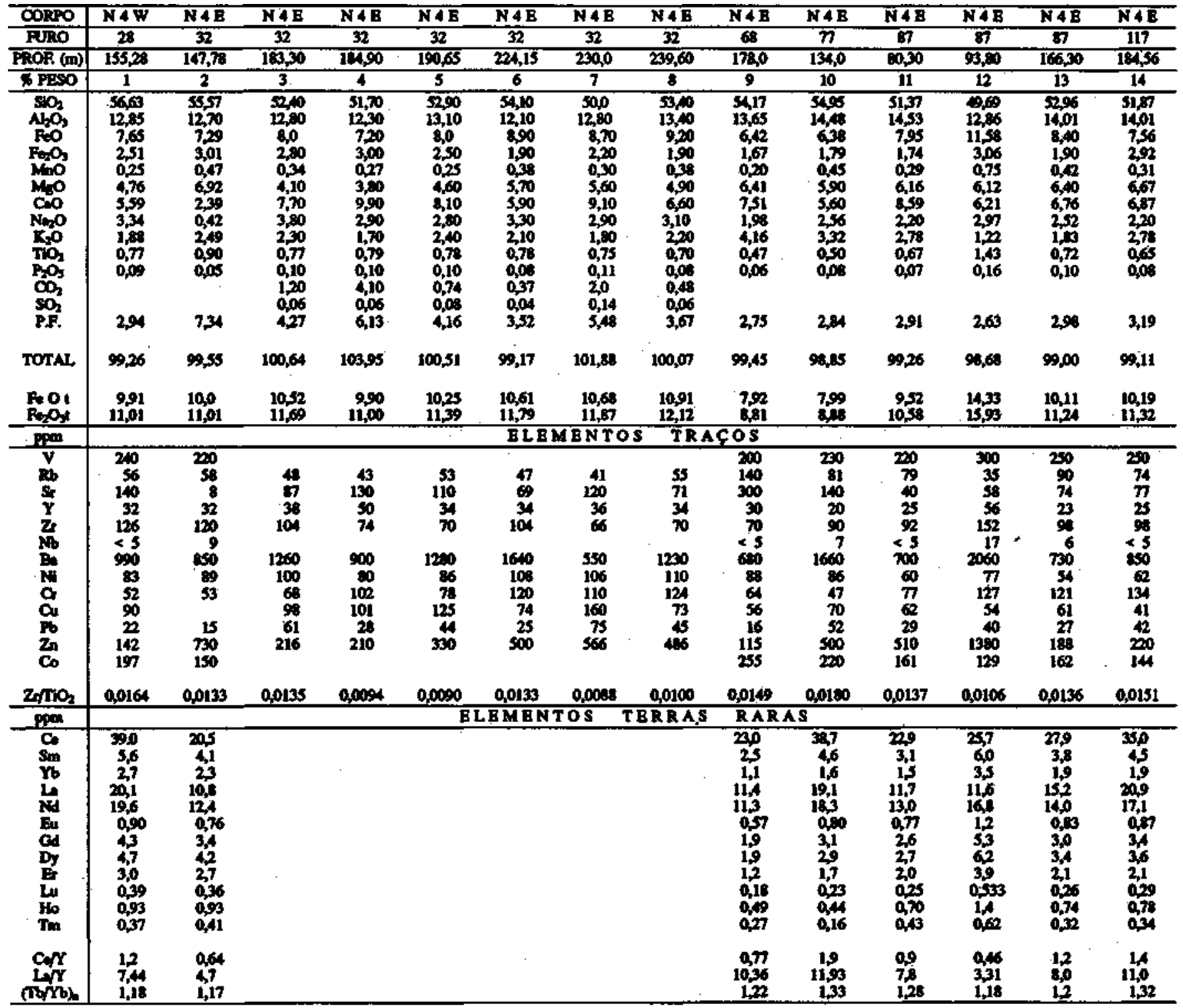


Tabela 1 - Continuação

Table 1 - Continuing

\begin{tabular}{|c|c|c|c|c|c|c|c|c|c|c|c|c|c|}
\hline CORPO & NAE & N4E & N4E & N4E & M E - 3* & $\mathrm{ME}-4^{*}$ & $\mathbf{N - 5}$ & N - 8 & N-8 & $\mathrm{N}-8$ & $N-E$ & \$.1I & $\$ \cdot 11$ \\
\hline FURO & 117 & 147 & 147 & 201 & - & - & 33 & 3 & 3 & 3 & 4 & 25 & 40 \\
\hline PROF (m) & 22650 & 199.25 & 281,0 & 115,70 & - & - & 107,73 & 16050 & 204,95 & 301,20 & 70,0 & 86,40 & 58,50 \\
\hline 5 PESO & 15 & $\overline{16}$ & 17 & 18 & 19 & 20 & 21 & 22 & 23 & 24 & 25 & 26 & 27 \\
\hline 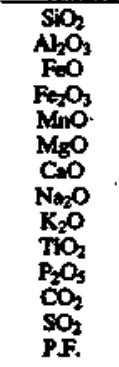 & $\begin{array}{l}51,07 \\
13,09 \\
9,13 \\
1,54 \\
0,42 \\
6,19 \\
6,11 \\
5,31 \\
3,70 \\
0,63 \\
0,09\end{array}$ & $\begin{array}{c}5,67 \\
13,77 \\
8,60 \\
7,84 \\
0,62 \\
5,82 \\
3,60 \\
3,03 \\
3,36 \\
0,78 \\
0,07\end{array}$ & $\begin{array}{l}54,16 \\
12,75 \\
9,45 \\
1,57 \\
0,71 \\
4,78 \\
6,14 \\
2,15 \\
4,05 \\
0,00 \\
0,06\end{array}$ & $\begin{array}{r}\mathbf{5 5 , 1 6} \\
\mathbf{1 4 , 4 5} \\
\mathbf{6 , 0 2} \\
2,01 \\
0,19 \\
6,27 \\
7,10 \\
2,55 \\
2,08 \\
0,52 \\
0,05\end{array}$ & $\begin{array}{r}53,60 \\
13,60 \\
8,60 \\
1,10 \\
0,50 \\
5,60 \\
7,20 \\
4,50 \\
1,50 \\
0,70 \\
0,08 \\
<0,05 \\
0,04 \\
2,54\end{array}$ & $\begin{array}{l}34,94 \\
13,99 \\
8,20 \\
0,75 \\
0,53 \\
5,78 \\
6,80 \\
4,56 \\
1,20 \\
0,60 \\
0,09\end{array}$ & $\begin{array}{c}56,37 \\
12,14 \\
5,14 \\
6,45 \\
0,14 \\
4,80 \\
0,58 \\
0,42 \\
7,83 \\
1,40 \\
0,23\end{array}$ & $\begin{array}{r}5,42 \\
13,49 \\
9,67 \\
1,58 \\
0,51 \\
7,37 \\
0,70 \\
1,53 \\
2,10 \\
0,87 \\
0,20\end{array}$ & $\begin{array}{c}53,76 \\
12,66 \\
10,50 \\
3,48 \\
0,64 \\
4,54 \\
3,69 \\
0,50 \\
3,13 \\
1,05 \\
0,12\end{array}$ & $\begin{array}{c}0,04 \\
14,10 \\
11,72 \\
2,01 \\
1,07 \\
7,21 \\
6,74 \\
0,45 \\
4,05 \\
1,08 \\
0,11\end{array}$ & $\begin{array}{r}55,99 \\
13,99 \\
8,99 \\
2,46 \\
0,35 \\
5,66 \\
2,56 \\
2,37 \\
1,98 \\
1,09 \\
0,22\end{array}$ & $\begin{array}{l}55,31 \\
14,66 \\
7,16 \\
0,66 \\
0,22 \\
6,13 \\
6,88 \\
2,28 \\
3,13 \\
0,45 \\
0,05\end{array}$ & $\begin{array}{l}55,20 \\
15,28 \\
5,88 \\
1,31 \\
0,17 \\
6,57 \\
7,26 \\
2,69 \\
1,89 \\
0,40 \\
0,07\end{array}$ \\
\hline TOTAL & 10027 & 99,74 & 98,92 & 9939 & 99,56 & 99,46 & 99,01 & 98,84 & 99,57 & 99,90 & 99,29 & 99,39 & 9,46 \\
\hline $\begin{array}{c}F=0, \\
F=O_{3},\end{array}$ & $\begin{array}{l}10,52 \\
11,69\end{array}$ & $\begin{array}{l}10,26 \\
11,40 \\
\end{array}$ & $\begin{array}{l}\mathbf{1 0 , 8 6} \\
\mathbf{1 2 , 0 7} \\
\end{array}$ & $\begin{array}{l}7,83 \\
8,70 \\
\end{array}$ & $\begin{array}{r}9,59 \\
10,66 \\
\end{array}$ & $\begin{array}{l}8,98 \\
9,96 \\
\end{array}$ & $\begin{array}{l}10,94 \\
12,16\end{array}$ & $\begin{array}{l}12,89 \\
14,53 \\
\end{array}$ & $\begin{array}{l}13,63 \\
15,15 \\
\end{array}$ & $\begin{array}{r}14,07 \\
15,60 \\
\end{array}$ & $\begin{array}{r}10,60 \\
11,78 \\
\end{array}$ & $\begin{array}{l}7,75 \\
8,62 \\
\end{array}$ & $\begin{array}{l}7,06 \\
7,84 \\
\end{array}$ \\
\hline $\mathrm{ppm}$ & & & & & & ELBMBN & Tos & BACYO & & & & & \\
\hline 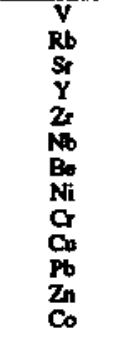 & $\begin{array}{r}250 \\
n 7 \\
84 \\
62 \\
94 \\
65 \\
600 \\
51 \\
67 \\
30 \\
31 \\
120 \\
126\end{array}$ & $\begin{array}{r}240 \\
69 \\
56 \\
16 \\
112 \\
65 \\
1000 \\
72 \\
43 \\
54 \\
10 \\
520 \\
144\end{array}$ & $\begin{array}{r}240 \\
110 \\
57 \\
18 \\
118 \\
<5 \\
3040 \\
70 \\
35 \\
13 \\
12 \\
410 \\
162\end{array}$ & $\begin{array}{r}240 \\
66 \\
160 \\
16 \\
84 \\
25 \\
1400 \\
94 \\
47 \\
70 \\
30 \\
110 \\
211\end{array}$ & $\begin{array}{r}41 \\
80 \\
30 \\
34 \\
680 \\
89 \\
148 \\
28 \\
59 \\
499\end{array}$ & $\begin{array}{r}200 \\
35 \\
75 \\
30 \\
120 \\
53 \\
520 \\
65 \\
110 \\
30 \\
13 \\
290 \\
101\end{array}$ & $\begin{array}{r}210 \\
170 \\
<5 \\
132 \\
320 \\
10 \\
2300 \\
54 \\
8 \\
44 \\
6 \\
\mathbf{2 4 0} \\
133\end{array}$ & $\begin{array}{r}240 \\
39 \\
24 \\
41 \\
112 \\
55 \\
1750 \\
82 \\
51 \\
250 \\
96 \\
560 \\
169\end{array}$ & $\begin{array}{r}250 \\
21 \\
140 \\
58 \\
172 \\
6 \\
2740 \\
47 \\
6 \\
167 \\
17 \\
550 \\
176\end{array}$ & $\begin{array}{r}240 \\
64 \\
28 \\
77 \\
100 \\
55 \\
2050 \\
122 \\
163 \\
56 \\
145 \\
2750 \\
245\end{array}$ & $\begin{array}{r}220 \\
41 \\
120 \\
230 \\
200 \\
8 \\
60 \\
94 \\
94 \\
78 \\
10 \\
190 \\
190 \\
130\end{array}$ & $\begin{array}{r}190 \\
120 \\
200 \\
12 \\
75 \\
\times 5 \\
1100 \\
89 \\
60 \\
80 \\
13 \\
110 \\
185\end{array}$ & $\begin{array}{r}192 \\
52 \\
260 \\
<10 \\
66 \\
55 \\
710 \\
94 \\
70 \\
69 \\
12 \\
120 \\
172\end{array}$ \\
\hline zatho & 0,0149 & 0,0144 & 0,0148 & 0,0162 & 0,0077 & 0,00200 & 0,0029 & 0,0129 & 0,0164 & 0,0093 & 0,0187 & 0,0167 & 0,0165 \\
\hline prn & & & & & E L E & MENTOS & TER & & RAS & & & & \\
\hline $\begin{array}{l}\mathrm{Ce} \\
\mathbf{S m} \\
\mathbf{Y b} \\
\mathbf{L} \\
\mathbf{N d} \\
\mathbf{E} \\
\mathbf{G} d \\
\mathbf{D y} \\
\mathbf{E} \\
\mathbf{L} \\
\mathbf{H o} \\
\mathbf{T}\end{array}$ & $\begin{array}{c}57,0 \\
7,2 \\
2,6 \\
30,0 \\
26,6 \\
0,98 \\
5,1 \\
5,2 \\
3,1 \\
0,38 \\
1,1 \\
0,51\end{array}$ & $\begin{array}{c}32,5 \\
4,2 \\
2,0 \\
17,9 \\
15,3 \\
1,1 \\
3,5 \\
3,6 \\
2,3 \\
0,35 \\
0,79 \\
0,43\end{array}$ & $\begin{array}{c}27,7 \\
3,3 \\
2,2 \\
14,5 \\
13,9 \\
0,63 \\
3,0 \\
3,4 \\
1,8 \\
0,31 \\
0,61 \\
0,25\end{array}$ & $\begin{array}{c}24,2 \\
2,6 \\
1,2 \\
12,3 \\
11,9 \\
0,65 \\
1,9 \\
2,0 \\
12 \\
0,18 \\
0,49 \\
0,21\end{array}$ & & $\begin{array}{c}23,9 \\
3,3 \\
1,7 \\
12,8 \\
12,7 \\
0,89 \\
3,4 \\
3,5 \\
22 \\
0,30 \\
0,77 \\
0,33\end{array}$ & $\begin{array}{c}\mathbf{1 6 5 , 3} \\
\mathbf{1 8 , 6} \\
\mathbf{5 , 9} \\
\mathbf{8 2 , 1} \\
\mathbf{7 5 , 1} \\
\mathbf{2 , 1} \\
\mathbf{1 3 , 0} \\
\mathbf{1 1 , 5} \\
\mathbf{6 , 5} \\
0,83 \\
2,3 \\
0,99\end{array}$ & $\begin{array}{c}4,3 \\
6,1 \\
2,8 \\
24,4 \\
22,6 \\
0,63 \\
4,70 \\
4,9 \\
2,9 \\
0,39 \\
0,96 \\
0,29\end{array}$ & $\begin{array}{c}59, \\
7,6 \\
3,3 \\
27,5 \\
25,7 \\
1,2 \\
5,6 \\
5,6 \\
3,6 \\
0,48 \\
1,4 \\
0,67\end{array}$ & $\begin{array}{r}51,4 \\
8,4 \\
3,4 \\
24,3 \\
27,4 \\
1,1 \\
6,3 \\
6,2 \\
3,7 \\
0,48 \\
1,2 \\
0,43\end{array}$ & $\begin{array}{c}290,2 \\
24,3 \\
5,1 \\
97,1 \\
95,6 \\
2,9 \\
15,8 \\
12,0 \\
6,1 \\
0,67 \\
2,3 \\
0,91\end{array}$ & $\begin{array}{c}32,9 \\
4,0 \\
1,5 \\
16,8 \\
16,3 \\
0,74 \\
2,8 \\
2,6 \\
1,7 \\
0,21 \\
0,44 \\
0,21\end{array}$ & $\begin{array}{c}2,2, \\
2,3 \\
1,1 \\
12,2 \\
12,3 \\
0,70 \\
2,0 \\
1,9 \\
1,1 \\
0,17 \\
0,32 \\
0,14\end{array}$ \\
\hline $\begin{array}{c}\mathrm{Cery} \\
\stackrel{4}{\mathrm{~Tb}} \\
(\mathrm{TW} / \mathrm{b})_{h}\end{array}$ & $\begin{array}{r}0,92 \\
11,54 \\
1,42\end{array}$ & $\begin{array}{l}2,0 \\
8,05 \\
1,29\end{array}$ & $\begin{array}{l}1,5 \\
6,59 \\
1,04\end{array}$ & $\begin{array}{r}1,5 \\
10,25 \\
1,17\end{array}$ & & $\begin{array}{l}0,8 \\
7,5 \\
1,46\end{array}$ & $\begin{array}{c}1,3 \\
13,9 \\
1,49\end{array}$ & $\begin{array}{l}1,2 \\
8,71 \\
1,22 \\
\end{array}$ & $\begin{array}{l}0,9 \\
8,73 \\
1,2\end{array}$ & $\begin{array}{l}0,67 \\
7,14 \\
1,28 \\
\end{array}$ & $\begin{array}{c}0,98 \\
19,0 \\
1,96\end{array}$ & $\begin{array}{r}2,7 \\
11,2 \\
1,29 \\
\end{array}$ & $\begin{array}{r}11,12 \\
1,28\end{array}$ \\
\hline
\end{tabular}

absorção atômica; $\mathrm{Na}_{2} \mathrm{O}$ e $\mathrm{K}_{2} \mathrm{O}$ - espectrometria de emissão pela chama; perda ao fogo - gravimetria.

NATUREZA DO VULCANISMO Os critérios químicos de classificação das rochas vulcânicas que melhor se adaptam às rochas espilitizadas do Grupo Grão-Pará envolvem as relações $\mathrm{SiO}_{2}-\mathrm{Zr} / \mathrm{TiO}_{2}$ e $\mathrm{Zr} / \mathrm{TiO}_{2}$-Ce. Desse modo, pode-se definir, com base nas figuras 2 e 3 , que as litologias analisadas pertencem, em sua maior parte, ao grupo dos andesitos basálticos $\left(\mathrm{SiO}_{2}\right.$ entre 52 e $\left.56 \%\right)$ de afinidade subalcalina e, subordinamente, a um grupo de rochas de composição mais alcalina.

As proporções relativas de elementos menos móveis $(\mathrm{Zr}$, Ti, Hf, Th e Ta) das rochas metabásicas do Grupo Grão-Pará (Figs. 4 e 5) sugerem um ambiente de arco magmático para a origem destas rochas.

GEOQUÍMICA DOS ELEMENTOS MAIORES

Os

elementos $\mathrm{TiO}_{2}, \mathrm{FeO}_{\mathrm{t}}, \mathrm{P}_{2} \mathrm{O}_{5}$ e V (Fig. 6) mostram comportamentos similares, com teores pouco variáveis, tendendo a decrescer à medida que aumenta o conteúdo de $\mathrm{SiO}_{2}$ das amostras. Miyashiro (1975) observou que Ti e V são carac-

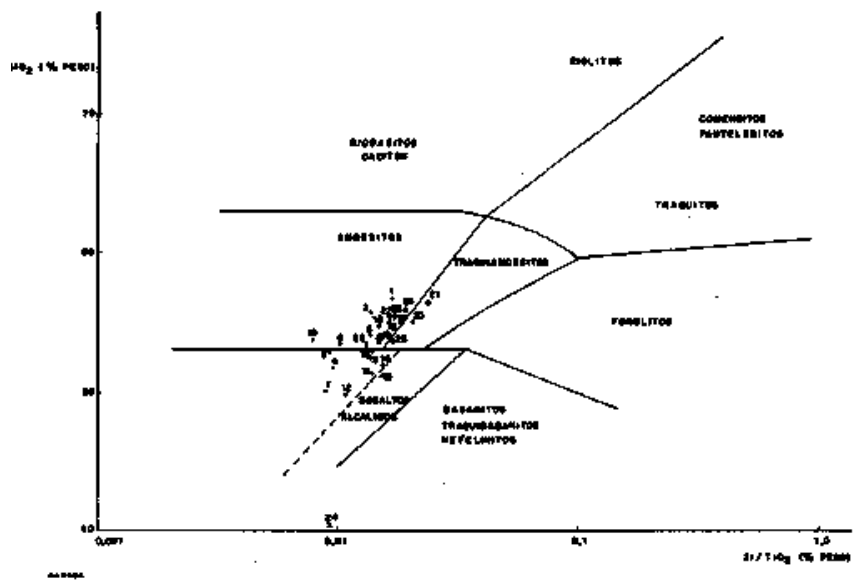

Figura 2 - Diagrama $\mathrm{SiO}_{2}-\mathrm{Zr} / \mathrm{TiO}_{2}$ de Winchester \& Floyd (1977) mostrando a delimitação dos campos de rochas vulcânicas comuns. Simbologia: Corpos N4 (.), Corpo N-8 (x), Corpo $\mathrm{S}-11(+)$ e Corpo $\mathrm{N}-5$ ( $\mathbf{\Delta})$

Figure $2-\mathrm{SiO}_{2}-\mathrm{Zr} / \mathrm{TiO}_{2}$ diagram (after Winchester \& Floyd 1977) for volcanic rocks. Symbology: Bodies N4 (.), Body N-8 (x), Body S-11 (+), and Body $\mathrm{N}-5(\boldsymbol{\Delta})$ 


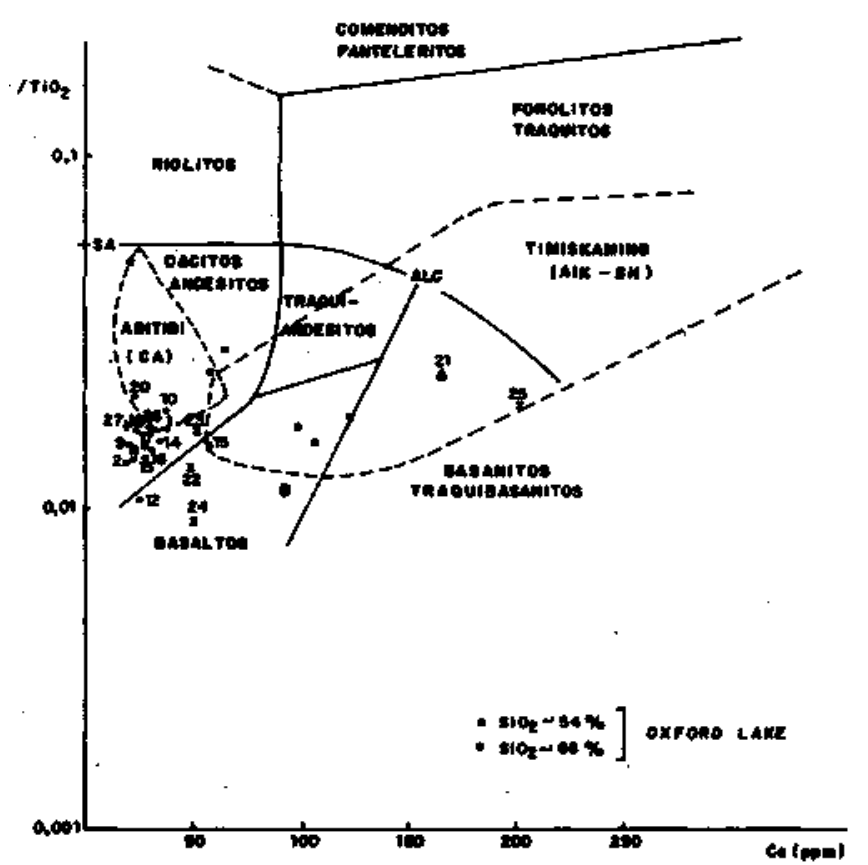

Figura 3 - Diagrama $\mathrm{Zr} / \mathrm{TiO}_{2}$-Ce mostrando a delimitação dos campos de rochas vulcânicas comuns, segundo Winchester \& Floyd (1977): $\boldsymbol{S A}$ são rochas vulcânicas subalcalinas de composição intermediária a félsica; $\boldsymbol{B}$ são basaltos subalcalinos ou alcalinos e ALC são rochas vulcânicas alcalinas. As relações $\mathrm{Zr} / \mathrm{TiO}_{2}$-Ce das rochas vulcânicas do Grupo Grão-Pará são comparadas com rochas vulcânicas arqueanas canadenses: vulcânicas cálcio-alcalinas do SW do Abitibi Belt (CA) e vulcânicas alcalinas-shoshoníticas de Timiskaming (ALK-SH) e de Oxford Lake. Os campos tracejados e os pontos de Oxford Lake foram compilados de Ujike (1985). Simbologia: Corpos N4 (.), Corpo N-8 (x), Corpo S-11(+)e Corpo $N-5$ ( $\mathbf{\Delta})$

Figure $3-\mathrm{Zr} / \mathrm{TiO}_{2}$-Ce diagram for volcanic rocks (after Winchester \& Floyd, 1977). Key to symbols: SA for subalkaline intermediate to felsic volcanic rocks; B for subalkaline or alkaline basalts; ALC for alkaline. Compared with Canadian Archean volcanic rocks: Abitibi Belt calco-alkaline volcanics (CA), Timiskaming alkaline-shoshonitic volcanics (ALK-SH) and Oxford Lake (open and full squares). Symbology: Bodies N4 (.), Body N-8 (x), Body S-11 (+), Body N-5 ( $\mathbf{\Delta})$

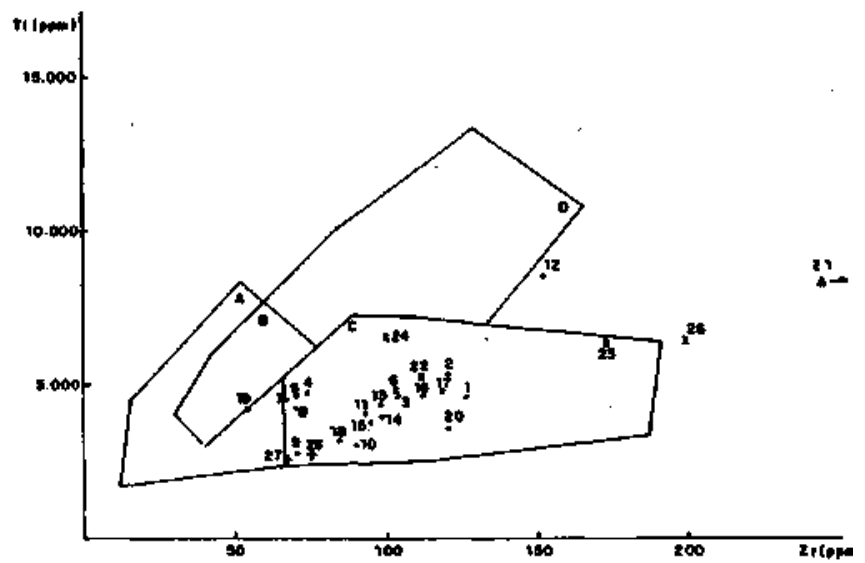

Figura 4 - Diagrama discriminante Ti-Zr de Pearce \& Conn (1973) indicando os campos dos toleitos de baixo $\boldsymbol{K}(\boldsymbol{A}$ e $\boldsymbol{B})$, basaltos cálcio-alcalinos ( $\boldsymbol{B}$ e $\boldsymbol{C}$ ) e basaltos de fundo oceânico (B e D). Simbologia: Corpos N4 (.), Corpo N-8 (x), Corpo $S-11(+)$ e Corpo N-5 ( $\mathbf{\Delta})$

Figure 4 - Ti-Zr Diagram (after Pearce \& Cann 1973) showing the fields of low $\mathrm{K}$ tholeiites (A and $\mathbf{B})$, calco-alkaline basalts $(\mathbf{B}$ and $\mathbf{C})$ and ocean floor basalts (B and D). Symbology: Bodies N4 (.), Body N-8 (x), Body S-11 (+), Body N-5 ( $\mathbf{\Delta})$

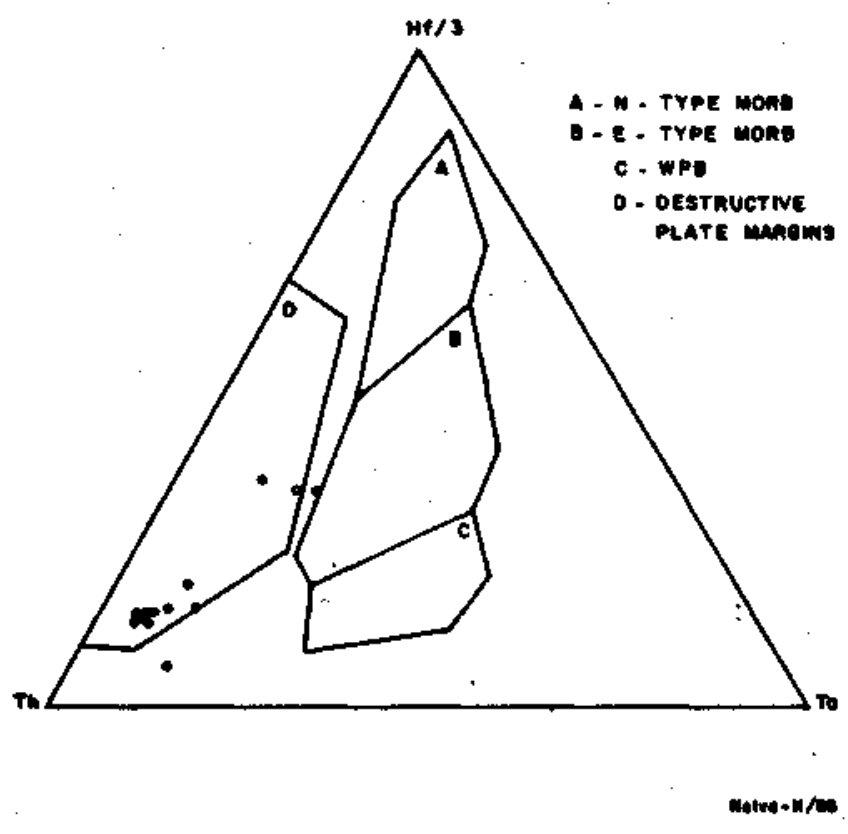

Figura 5 - Diagrama Hf/3 -Th-Ta para as rochas basálticas do Grupo Grão-Pará. Os campos foram obtidos de Wood et al. (1979) e as análises químicas são de Gibbs et al. (1986) Figure $5-\mathrm{Hf} / 3$ - Th - Ta diagram (after Wood et al 1986) for Grão-Pará basaltic rocks. The chemical analysis are from Gibbs et al (1986)

teristicamente concentrados na magnetite, juntamente com o $\mathrm{Fe}$, e mostram comportamentos similares ao do $\mathrm{FeO}_{\mathrm{t}}$ na cristalização fracionária das séries toleíticas (aumento de FeO com o avanço do fracionamento) e cálcio-alcalinas (decréscimo de $\mathrm{FeO}_{\mathrm{t}}$ com o avanço do fracionamento). Portanto, os trends delineados pelos pontos correspondentes a $\mathrm{TiO}_{2}, \mathrm{FeO}$ e $\mathrm{V}$ na figura 6 são típicos de magmas cálcio-alcalinos. $\mathrm{O}$ trend do $\mathrm{P}_{2} \mathrm{O}_{5}$ do corpo N4 é semelhante ao encontrado por Gill (1981) para os andesitos orogênicos das séries cálcio-alcalinas, onde o conteúdo de $\mathrm{P}_{2} \mathrm{O}_{5}$ geralmente permanece constante ou diminui, com o aumento da silica; o inverso é válido para as séries toleíticas.

Todas as rochas vulcânicas extravasadas em margens de placas convergentes têm distintamente baixo teor de $\mathrm{TiO}_{2}$ (Pearce \& Cann 1973). Este fato vem fortalecer, mais uma vez, a idéia de um ambiente de arco para as rochas vulcânicas dos corpos N4 e N8, em razão dos baixos teores de $\mathrm{TiQ}_{2}$ encontrados para estas rochas (Tab. 1).

$\mathrm{Na}$ química de elementos maiores de um arco magmático, a distinção fundamental entre as séries toleítica, cálcio-alcalina e shoshonítica é o aumento progressivo, nesta ordem, do conteúdo de álcalis. Como o K é o principal indicador desse aumento (Jakes \& White 1972, Hughes 1982, Ewart 1982), é utilizado como elemento discriminante entre as diferentes séries magmáticas.

Embora haja possibilidade de alguns derrames dos corpos N4 e N8 terem sofrido adição de K durante a alteração, os teores invariavelmente altos deste elemento em todas as amostras analisadas sugerem um magma originalmente rico em $\mathrm{K}$ para esses corpos. A utilização do diagrama de Peccerillo \& Taylor (1976) revela que as amostras são distribuídas pelos campos das séries cálcio-alcalina, cálcio-alcalina alto $\mathrm{K}$ e principalmente shoshonítica (Fig. 7).

\section{GEOQUÍMICA DOS ELEMENTOS TRAÇOS Uma} comparação dos teores de elementos traços das amostras estudadas com aqueles apresentados por vários autores (Jakes \& White 1972, Morrison 1980, Pearce 1982, Ujike 1985) para 


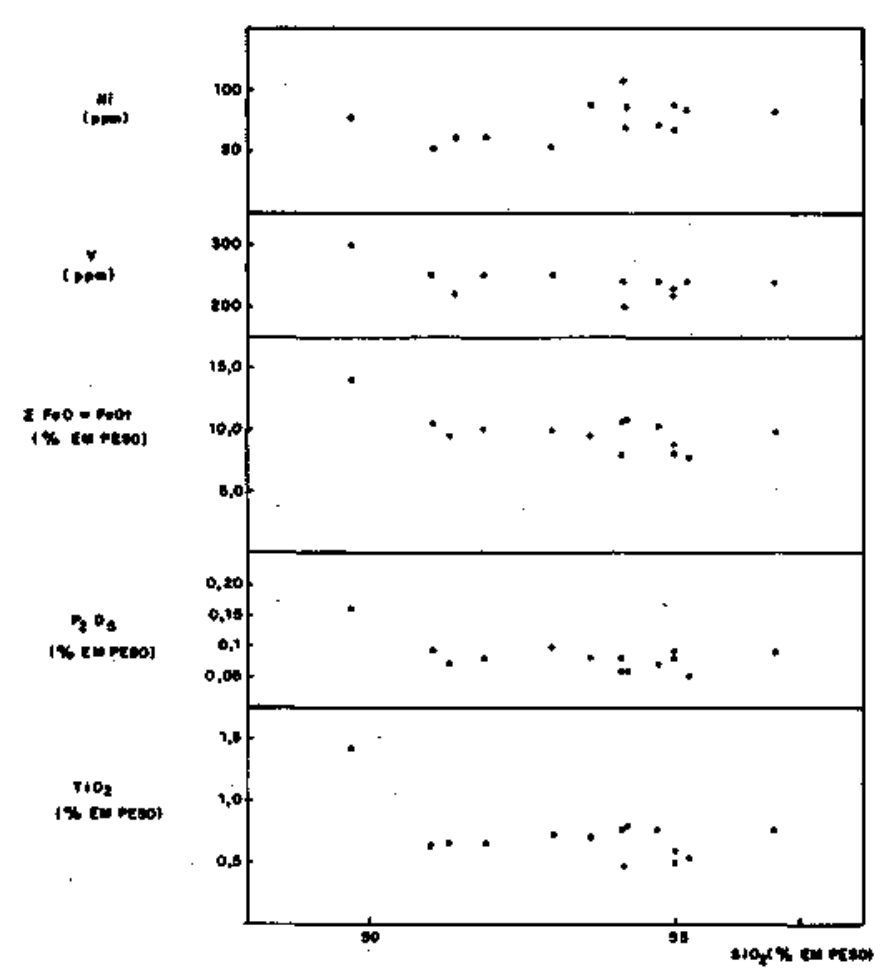

Figura 6 - Variação de alguns elementos maiores e traços em relação ao teor de $\mathrm{SiO}_{2}$ nas rochas vulcânicas do Corpo N4

Figure 6 - Variation of some major and trace elements with $\mathrm{SiO}_{2}$ in $\mathrm{N} 4$ volcanic rocks

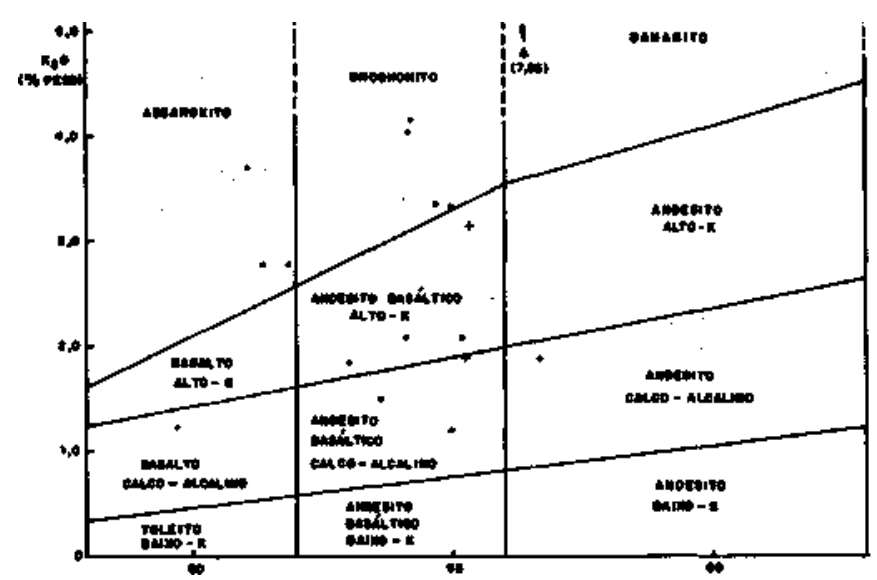

Figura 7 - Diagrama relacionando $\mathrm{K}_{2} \mathrm{O}-\mathrm{SiO}_{2}$ para as rochas vulcânicas do Grupo Grão-Pará. A separação dos campos é baseada em Peccerillo \& Taylor (1976). Simbologia: Corpo $S-11(+)$ e Corpo N4E (.)

Figure $7-\mathrm{K}_{2} \mathrm{O}-\mathrm{SiO}_{2}$ diagram (after Peccerillo \& Taylor 1976) for Grão-Pará volcanic rocks. Symbology: Body S-11 (+), Body N4E (.)

as diferentes séries magmáticas permite reconhecer nas rochas vulcânicas do Grupo Grão-Pará afinidades cálcio-alcalina, cálcio-alcalina "transicional", alcalina e principalmente shoshonítica (Tab. 2).

O conteúdo dos elementos traços Rb (50 - 140 ppm) e Ba (520 - $3040 \mathrm{ppm}$ ) define um intervalo de valores que, embora mostrem alguma dispersão devido à alteração hidrotermal, são típicos da série snoshonítica. Portanto, os altos teores de $\mathrm{Ba}$ e $\mathrm{Rb}$, associados aos baixos teores de $\mathrm{Zr}$ e $\mathrm{Nb}$ (8 - 10 ppm), foram considerados aqui como conteúdos diagnósticos para a caracterização de uma série shoshonítica para a maior parte das rochas vulcânicas encontradas nos corpos N4 e N8.

Tabela 2 - Quadro composicional comparativo entre as diversas séries de arco magmático e suas possíveis correlações com as rochas vulcânicas do Grupo Grão-Pará. Os teores dos elementos foram compilados de Jakes \& White (1972), Morrison (1980), Pearce (1982) e Ujike (1985)

Table 2 - Comparison between the various magmatic arc series and the Grão-Pará volcanic rocks. The data for the elements were compiled from Jakes \& White (1972), Morrison (1980), Pearce (1982) and Ujike (1985)

\begin{tabular}{|c|c|c|c|c|c|}
\hline \multirow{4}{*}{$\begin{array}{c}\text { ELEMENTOS } \\
\text { MAIORES (\$ PESO) } \\
\text { E TMAOOS (ppo) }\end{array}$} & \multicolumn{5}{|c|}{ SERTES MAOMATICAS DE MARCEM DE PLACAS CONVERGENIES } \\
\hline & TOLETICA & CÁLCIO-ALCALINA & \multirow{2}{*}{\multicolumn{2}{|c|}{$\begin{array}{c}\text { SFOSHONTICAS } \\
\text { INTERVALO DE StO }{ }_{2}\end{array}$}} & ALCATEN \\
\hline & TNTERVALO DE STO & DNTERVALO DE SHO & & & DNERYALO DE SO, \\
\hline & $52 \cdot 58 \%$ & $50-58 \%$ & $48-538$ & $53-57 \%$ & $51-57 \%$ \\
\hline $\mathrm{K}_{7} \mathrm{O}$ & $0,44-0,43$ & $1,07-1,27^{\circ}$ & $2,74(1,52-4,65)$ & $3,66(2,40 \cdot 6,05)$ & 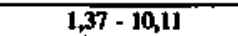 \\
\hline $\mathbf{T O _ { 2 }}$ & $0,80-1,25$ & $0,76 \cdot 1,05$ & $0,83(0,18-1,55)$ & $0,93(0,68 \cdot 1,84)$ & $0,63+1,05$ \\
\hline$\overline{P_{z} O_{3}}$ & $0,11-0,44$ & $0,20-0,21$ & $0,44(0,22-0,74)$ & $0,60(0,01-1,4)$ & $0,23-1,14$ \\
\hline $\mathbf{R} \mathbf{b}$ & $5,0-6,0$ & $10 \cdot 30$ & $59(24-187)$ & $63(14 \cdot 109)$ & $72-302$ \\
\hline$\overline{\mathbf{B}} \mathbf{a}$ & $75-100$ & $115-270$ & $683(360-992)$ & $567(370-1011)$ & $1500-5200$ \\
\hline $\mathbf{s i}$ & $200-220$ & $330-385$ & $943(520-2010)$ & $956(485-1473)$ & $740=1780$ \\
\hline$\overline{\mathrm{Ni}}$ & $30-20$ & $25-18$ & $50 \quad(4-340)$ & $53 \quad(9-145)$ & $7-26$ \\
\hline $\mathbf{v}$ & $270 \cdot .175$ & $255-175$ & $290(195-670)$ & $218(105-300)$ & 145.369 \\
\hline$\overline{C r}$ & $50-15$ & $40-25$ & $156 \quad(2-600)$ & $141(13-440)$ & $<5.86$ \\
\hline $\mathbf{Z}$ & 70 & $100-11 \overline{0}$ & $67(26-277)$ & $121 \quad(81-180)$ & $180 \cdot-49$ \\
\hline $\mathbf{M}$ & $1,7^{*}$ & $2,7^{*}$ & $8,4^{*}$ & - & $=$ \\
\hline $\mathbf{Y}$ & $\overline{17}$ & $20-2 \overline{1}$ & $16(11-41)$ & $1 \overline{18 \quad(15 \cdot 26)}$ & $17-41$ \\
\hline$C_{e}$ & 6,94* & $19-24$ & \multicolumn{2}{|c|}{$28-35$} & $168-329$ \\
\hline $\mathrm{La/Pb}$ & 1,0 & $3,5-6,2$ & \multirow{2}{*}{\multicolumn{2}{|c|}{$6,6+15$}} & - \\
\hline$Y_{\mathbf{y}}$ & $1,4-2,4$ & $2,7-1,9$ & & & $2,12 \cdot 3,26$ \\
\hline$\overline{\mathbf{L}}$ & $1,1=2,4$ & $9,6-11,9$ & \multicolumn{2}{|c|}{$\frac{2,1+1,2}{14+18}$} & $89-137$ \\
\hline $\begin{array}{c}\text { CORREIACKO } \\
\text { APROXMMADA DAS } \\
\text { AMOSTRAS DO } \\
\text { GRUPO GRAO-PARA }\end{array}$ & & \multicolumn{3}{|c|}{$\begin{array}{l}(1) *(2),(3),(4),(5),(6),(7) \\
(12) *(8),(9),(10),(11),(13),(14) \\
(19) *(15),(16),(17),(18),(22),(23) \\
(20) *(24),(26), 27)\end{array}$} & $(21,25)$ \\
\hline
\end{tabular}

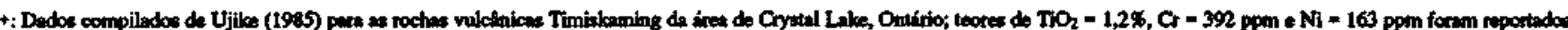
por Capdevila et at. (19\%2), in Ufiliee (1985)

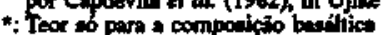

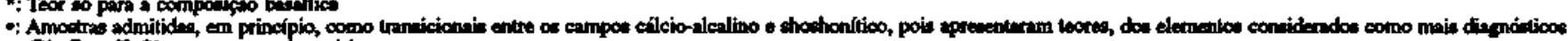
$\left(\mathrm{Rb}, \mathrm{Ba}\right.$ \& $\mathrm{K}_{2} \mathrm{O}$ ), comun anber séries 
A figura 3 mostra que os pontos analíticos referentes às rochas vulcânicas de afinidade alcalina do Grupo Grão-Pará caem dentro do campo composicional das rochas vulcânicas Timiskaming, enquanto o restante das análises são projetadas no campo das rochas subalcalinas. As rochas vulcânicas intermediárias de Oxford Lake, projetadas no campo delimitado pelas vulcânicas Timiskaming, são consideradas andesíticas de alto $\mathrm{K}$ a shoshoníticas, com base principalmente na relação $\mathrm{K}_{2} \mathrm{O}-\mathrm{SiO}_{2}$ e nos padrões de distribuição das terras raras (Brooks et al. 1982). Portanto, pelas relações observadas na figura 3, as rochas vulcânicas do Grupo Grão-Pará, na área de estudo, podem estar indicando a presença de uma suíte vulcânica composta por rochas de natureza shoshonítica-alcalina semelhante à de Oxford Lake.

O padrão enriquecido em terras raras leves, mostrado pela figura 8, é característico de rochas vulcânicas mais evoluídas associadas a eventos orogênicos. A similaridade no enriquecimento das terras raras leves, comumente observada nas séries cálcio-alcalina, shoshonítica e alcalina, contribui para a freqüente superposição dos seus padrões de distribuição, dificultando, desta forma, um diagnóstico preciso entre elas (Jakes \& Gill 1970, Morrison 1980, Ujike 1985). A difícil separação entre as séries cálcio-alcalina e shoshonítica reside na fraca correlação existente entre o $\mathrm{K}_{2} \mathrm{O}$ e a razão $\mathrm{La} / \mathrm{Yb}$ nos arcos magmáticos (Jakes \& Gill 1970).

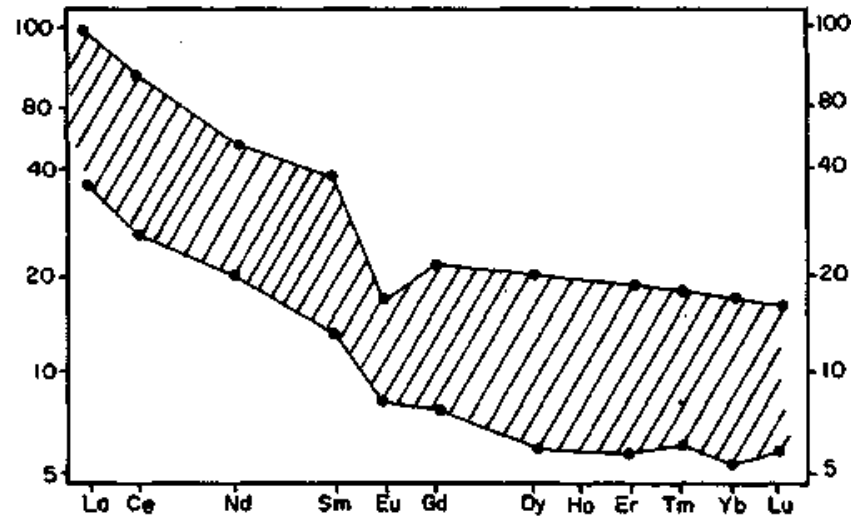

Figura 8 - Intervalo de padrões de REE normalizados a condritos para as rochas basálticas do Grupo Grão-Pará Figure 8 - REE (normalized to chondrites) distribution patterns for Grão-Pará basaltic rocks

As características predominantes das rochas vulcânicas do Grupo Grão-Pará e das séries magmáticas de margem de placas convergentes foram resumidas e agrupadas na tabela 3.

Tabela 3 - Quadro comparativo das características principais das rochas vulcânicas do Grupo Grão-Pará (Corpos N4 e N8) e das séries magmáticas de margem de placas convergentes. As diversas informações envolvendo as séries de arco magmático foram obtidas de Jakes \& Gill (1970), Jakes \& White (1971, 1972), Morrison (1980), Bailey (1981), Pearce (1982) e Ujike (1985)

Table 3 - Comparison between the principal Grão-Pará volcanic rocks (Bodies N4 and N8) and the magmatic series of destructive plates. The data for the elements were compiled from Jakes \& Gill (1970), Jakes \& White (1971, 1972), Morrison (1980), Bailey (1981), Pearce (1982), and Ujike (1985)

\begin{tabular}{|c|c|c|c|c|c|}
\hline \multirow{2}{*}{$\begin{array}{c}\text { CARACTERISTKCAS } \\
\text { GERAIS }\end{array}$} & \multirow{2}{*}{$\frac{\text { CORPOS }}{\mathrm{N}-\mathrm{EN} \mathrm{N}-\mathrm{8}}$} & \multicolumn{4}{|c|}{ SERIES MAGMATICAS DE MARGEM DE PLACAS CONVERGENTES } \\
\hline & & TOLEfTICA & CALCKOALCALINA & SHOSHONITACA & ALCALINA \\
\hline Fenocristain & 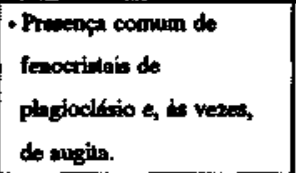 & \multicolumn{2}{|c|}{ 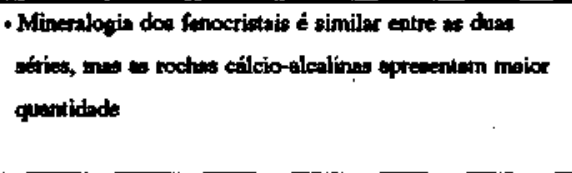 } & 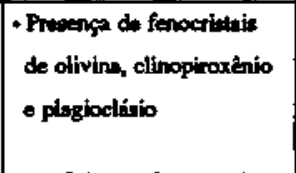 & \\
\hline Elementas diagnóticos & 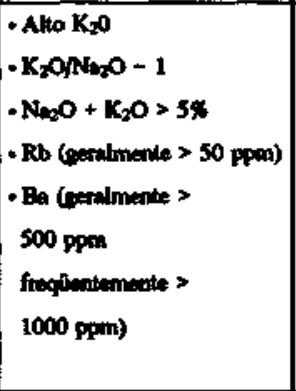 & $\begin{array}{l}\text { - Bairo K (-0,44s) } \\
\text { - Rb } 3 \text { - } 10 \mathrm{ppm} \\
\text { - St } 100 \text { - } 200 \mathrm{ppm} \\
\text { - B } 50 \text { - } 150 \mathrm{pmm}\end{array}$ & $\begin{array}{l}\text { - K 1,0 - 1,35 } \\
\text { - } \mathrm{Ab} 30 \mathrm{ppm} \\
\text { - St } 360 \mathrm{ppm} \\
\text { + B4, } 270 \mathrm{pmm}\end{array}$ & 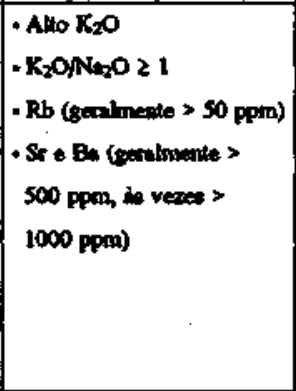 & 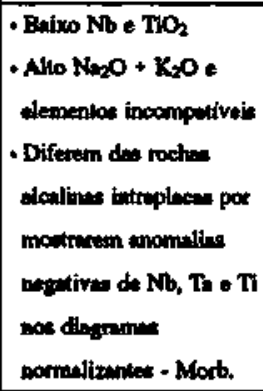 \\
\hline $\begin{array}{l}\text { Veriagio de algune } \\
\text { elementos com } \mathrm{SOO}_{2}\end{array}$ & 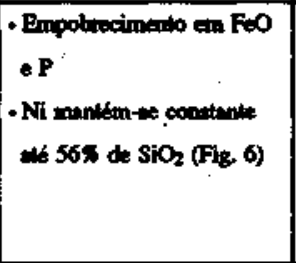 & 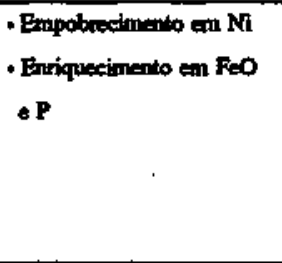 & 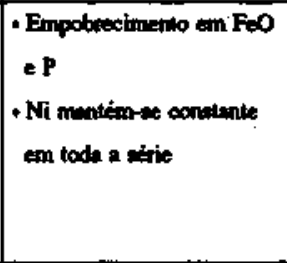 & 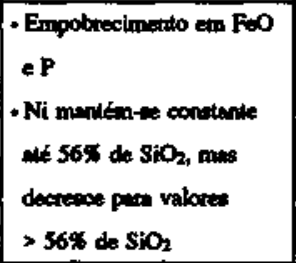 & . \\
\hline $\begin{array}{l}\text { Padros de didribuicio } \\
\text { du REE }\end{array}$ & 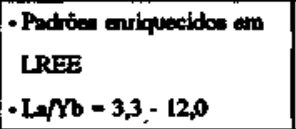 & 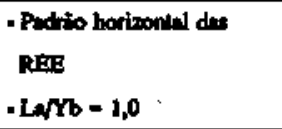 & \multicolumn{3}{|c|}{ 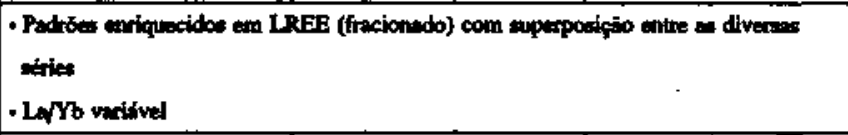 } \\
\hline $\begin{array}{l}\text { Proporgited reletives } \\
\text { erte a rocher }\end{array}$ & 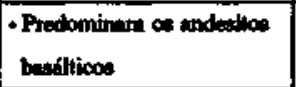 & - Phedominem os bollos & $\begin{array}{l}\text { - Phedominam anderilos e } \\
\text { andesilos bueslitios }\end{array}$ & 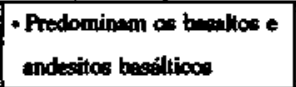 & \\
\hline 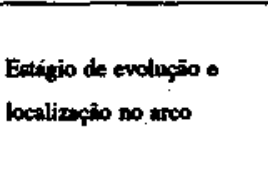 & 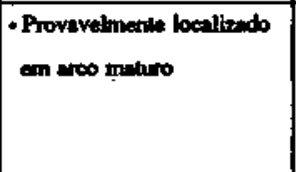 & $\begin{array}{l}\text { - Eathio ivicial de } \\
\text { onohyto do teo } \\
\text { - Proxim of foum oceliniea }\end{array}$ & 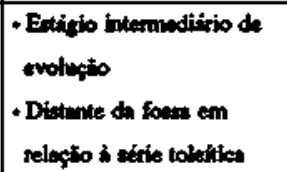 & \multicolumn{2}{|c|}{ 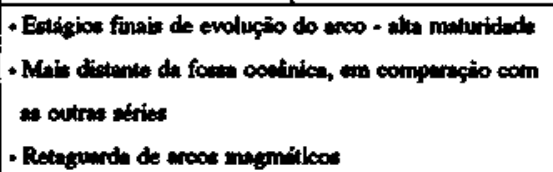 } \\
\hline
\end{tabular}


PETROGÊNESE Entre os vários modelos petrogenéticos que têm sido propostos para explicar as características químicas das rochas shoshoníticas, destacam-se os seguintes: - fusão parcial de um manto enriquecido em elementos "LIL" (large-ion-lithophile) por Dostal et al (1977), com composições variando de espinélio lherzolito (Carr \& Fardy 1983) a granada ou espinélio peridotito (Dostal \& Zerbi 1978, Manetti et al 1979);

- fusão de rochas do manto, com enriquecimento em elementos litófilos, decorrente da assimilação de rochas crustais. Esta assimilação pode ser explicada pelas altas razões ${ }^{87} \mathrm{Sr} /{ }^{86} \mathrm{Sr}(0,7054-0,7100)$ das rochas shoshoníticas (Tsvetkov 1984).

De acordo com Meirelles (1986), os padrões de terras raras das rochas de afinidade shoshonítica do Grupo Grão-Pará são condizentes com o modelo petrogenético proposto por Manetti et al. (1979), que sugerem uma região fonte do manto enriquecida em elementos "LIL". A possibilidade de um enriquecimento adicional destes elementos por contaminação crustal também é viável, uma vez que Gibbs et al (1986) obtiveram uma razão ${ }^{87} \mathrm{Sr} /{ }^{86} \mathrm{Sr}$ de 0,7057 para as rochas vulcânicas do Grupo Grão-Pará.

AMBIENTE GEOTECTÔNICO Em termos geotectônicos, as rochas vulcânicas do Grupo Grão-Pará não estão bem definidas. Medeiros Neto \& Villas (1985), adotando o modelo proposto por Hutchinson (1979), acreditam que o Grupo Grão-Pará e as Seqüências Buritirama e Salobo-Pojuca sejam representantes de diferentes fácies de uma única seqüência vulcanossedimentar. Ferreira Filho (1985) define um ambiente de arco de ilhas para as rochas metabásicas do Prospecto Bahia, e, por meio de critérios petrográficos e geo- químicos, correlaciona estas rochas com aquelas do Grupo Grão-Pará.

As evidências geoquímicas apresentadas neste trabalho sugerem que as rochas basálticas do Grupo Grão-Pará representam um magmatismo predominantemente shoshonítico, que possivelmente ascendeu até a superfície por um sistema de rifles formado em ambiente de crosta continental, ligado geneticamente a uma orogênese vizinha.

O modelo geotectônico proposto neste trabalho difere daquele apresentado por Wirth (1986) e Gibbs et al (1986), principalmente no que diz respeito à origem do mecanismo de rifteamento. Como este mecanismo se relaciona ao processo de subducção (Meirelles 1986, Dardenne et al 1988), o modelo proposto não favorece uma comparação com basaltos do tipo Karoo e Bacia do Paraná como sugerem tais autores, pois os baixos teores de $\mathrm{Ti}$, $\mathrm{Nb}$ e $\mathrm{Zr}$ (elementos considerados relativamente imóveis) das rochas basálticas "Grão-Pará" não estão de acordo com os (altos) teores encontrados para esses mesmos elementos nos basaltos daquelas províncias.

Segundo os autores, o ambiente geotectônico do Grupo Grão-Pará se assemelha em muitos aspectos com a evolução do mar do Japão (Windley 1984).

Agradecimentos Os autores agradecem aos funcionários do laboratório de Geoquímica da Universidade de Brasília $(\mathrm{UnB})$ pelas determinações analíticas, bem como às companhias de mineração DOCEGEO e Vale do Rio Doce pelo apoio dado ao projeto. Este trabalho foi realizado com o auxílio do Conselho Nacional de Pesquisa e Desenvolvimento (CNPq) (Processo No 405267-84), CAPES e Programa de Apoio ao Desenvolvimento Científico e Tecnológico (PADCT).

\section{REFERÊNCIAS BIBLIOGRÁFICAS}

BAILEY, J.C. 1981. Geochemical criteria for a refined tectonic discrimination of orogenic andesites. Chem. Geol, 32:139-154.

BARBOSA, O.; ANDRADE RAMOS, J.R.; GOMES, F.A.; HEMBOLD, R. 1986. Geologia estratigráfica, estrutural e econômica da área do Projeto Araguaia. Rio de Janeiro, DNPM/DGM. 95 p. (Monografia 19).

BEISIEGEL, V.R.; BERNARDELLI, A.L.; DRUMMOND, N.F.; RUFF, A.W.; TREMAINE, J.W. 1973. Geologia e recursos minerais da Serra dos Carajás. Rev. Bras. Geoc., 3(4):215-242.

BROOKS, C.; LUDDEN, J.; PIGEON, Y.; HUBREGTSE, J.J.M.W. 1982. Volcanism of shoshonite to high-K andesite affinity in an Archean arc environment, Oxford Lake, Manitoba. Can. J. Earth Sci., 19:55-67.

CARR, P.P. \& FARDY, J.J. 1983. REE geochemistry of Late Permian shoshonitic lavas from the Sydney Basin, New South Wales, Australia. Chem. Geol, 43:187-201.

DARDENNE, M.A.; FERREIRA, CR, P; MEIRELLES, M.R. 1988. The role of shoahonitic and calc-alkaline suites in tectonic evolution of the Carajás District, Brazil. South Am. Earth Sci., 1(4):363-372.

DICKINSON, W.R.; RICHARD, M.J.; COULSON, F.I.; SMITH, J.G.; LAWRENCE, R.L. 1968. Late Cenozoic shoshonitic lavas in North-Western Vite Levu, Fiji. Nature, 219:148.

DOSTAL, J.; ZENTILLI, M.; CAELLES, J.C.; CLARK, A.H. 1977. Geochemistry and origin of volcanic rocks of the Andes $\left(26^{\circ}-28^{\circ} \mathrm{S}\right)$. Contrib. Mineral. Petrol., 63:113-128.

DOSTAL, J. \& ZERBI, M. 1978. Geochemistry of the Savalan volcano (Northwestern Iran). Chem. Geol, 22:31-42.

EWART, A. 1982. The mineralogy and petrology of Tertiary-Recent orogenic volcanic rocks: with special reference to the andesitic-basaltic compositional range. In: THORPE, R.S. ed. Andesites: orogenic andesites and related rock. New York, Wiley \& Sons. p. 25-95.

FARIAS, N.F.; SANTOS, A.B.S.; BIAGINI, D.O.; VIEIRA, E.A.P.; MARTINS, L.P.B.; SAUERESSIG, R. 1984. Jazidas de Cu e Zn da Area Pojuca, Serra dos Carajás - PA. In: CONOR. BRAS. GEOL., 33. Rio de Janeiro, 1984. Anais... Rio de Janeiro, SBG. v. 8, p. 3658-3668.

FERREIRA, C.F., P 1985. Geologia e mineralizações sulfetadas do Prospecto Bahia, Província Mineral de Carajás. Brasília. 112 p. (Dissertação de Mestrado, IG/UnB). (Inédito).

FERREIRA, C.F., P \& DANNI, J.C.M. 1985. Petrologia e mineralizações sulfetadas do Prospecto Bahia - Carajás. In: SIMP. GEOL. AMAZ., 2. Belém, 1982. Anais... Belém, SBG. v. 3, p. 34-47.

GIBBS, A.K.; WIRTH, K.R.; HIRATA, W.K.; OLSZEWSKI, W.J. 1986. Age and composition of the Grão-Pará group volcanics, Serra dos Carajás. Rev. Bras. Geoc., 16(2):201-211.
GILL, J.B. 1970. Geochemistry of Viti Levu, Fiji, and its evolution as an island arc. Contr. Mineral. Petrol., 27:179-203.

GILL, J.B. 1981. Orogenic Andesites and Plate Tectonics. Berlin, SpringerVerlag. 390 p.

HIRATA, W.K.; RIGON, J.C.; KADEKARU, K.; CORDEIRO, A.A.C.; MEIRELES, E.M. 1982. Geologia Regional da Província Mineral de Carajás. In: SIMP. GEOL. AMAZ., 1. Belém, 1982. Anais... Belém, SBG. p. $100-108$.

HUGHES, C.J. 1982. Igneous petrology. New York, Elsevier. 551 p.

HUTCHINSON, R.W. 1979. Report on DOCEGEO Copper Projects MM1, Salobo and regional geological relationship, Pará, Brazil. Belém, DOCEGEO. 17 p. (Rel. Int.).

JAKES, P. \& GILL, J. 1970. Rare earth elements and the island arc tholeiitic series. Earth Planet. Sci. Letters, 9:17-28.

JAKES, P. \& WHITE, A.J.R. 1971. Composition of island arcs and continental growth. Earth Planet. Sci. Lett., 12:224-230.

JAKES, P. \& WHITE, A.J.R. 1972. Major and trace element abundances in volcanic rocks of orogenic areas. Geol Soc. Amer. Bull, 83:29-40.

JOPLIN, G.A.; KISS, E.; WARE, N.G.; WIDDOWSON, J.R. 1972. Some chemical data on members of the shoshonite association. Mineral. Mag., 38:936-945.

MACKENZIE, D.E. \& CHAPPEL, B.W. 1972. Shoshonitic and calc-alkaline lavas from the highlands of Papua New Guinea. Contr. Mineral. Petrol., 35:50-62.

MANETTI, P.; PECCERILLO, A.; POLI, G. 1979. REE distribution in Upper Cretaceous calc-alkaline and shoshonitic volcanic rocks from Eastern Srednogorie (Bulgaria). Chem. Geol, 26:51-63.

MEDEIROS, F.A., NETO \& VILLAS, R.N.N. 1985. Geologia da jazida de $\mathrm{Cu}-\mathrm{Zn}$ do Corpo 4E-Pojuca, Serra dos Carajás. In: SIMP. GEOL. AMAZ., 2. Belém, 1985. Anais... Belém, SBG. v. 3, p. 97-112.

MEIRELES, E.M.; HIRATA, W.K.; AMARAL, A.F.; MEDEIROS, C.A., P; GATO, W.C. 1984. Geologia das Folhas Carajás e Rio Verde, Província Mineral dos Carajás, Estado do Pará. In: CONOR. BRAS. GEOL., 33. Rio de Janeiro, 1984. Anais... Rio de Janeiro, SBG. v. 5, p. 2164-2174.

MEIRELLES, M.R. 1986. Geoquímica e petrologia dos jaspilitos e rochas vulcânicas associadas, Grupo Grão-Pará, Serra dos Carajás - PA. Brasília. 150 p. (Dissertação de Mestrado, IG/UnB). (Inédito).

MIYASHIRO, A. 1975. Volcanic rock series and tectonic setting. Ann. Rev. Earth Planet. Sci., p. 251-269.

MORRISON, G.W. 1980. Characteristics and tectonic setting of the shoshonite rock association. Lithos, 13:97-108. 
PEARCE, J.A. 1982. Trace element characteristics of lavas from destructive plate boundaries. In: THORPE, R.S. ed. Andesites: erogenic andesites and related rocks. New York, Wiley \& Sons. p. 525-548.

PEARCE, J.A. \& CANN, J.R. 1973. Tectonic setting of basic volcanic rocks determined using trace element analyses. Earth Planet. Sci. Lett., 19:290-300

PECCERILLO, A. \& TAYLOR, S.R. 1976. Geochemistry of Eocene calc-alkaline volcanic rocks from the Kastamonu area, Northern Turkey. Contr. Miner. Petrol, 58:63-81.

SILVA, G.G.; LIMA, M.I.C.; ANDRADE, A.R.F.; ISSLER, R.S.; GUIMARÃES, G. 1974. Geologia. In: LEVANTAMENTO DE RECURSOS NATURAIS. Projeto Rodam: Folha SB.22 Araguaia e pane da Folha SC.22 Tocantins. Rio de Janeiro, MME-DNPM. v. 4, 143 p.

TSVETKOV, A.A. 1984. Subalkaline basaltic magmatism in active zones of transition from ocean to continent. Inter. Geol Rev., 26:889-906.

UJIKE, O. 1985. Geochemistry of Archean alkalic volcanic rocks from the Crystal Lake area east of Kirkland Lake, Ontario, Canada. Earth. Planet. Sci. Lett., 73:333-344.

VENTURELLI, G.; THORPE, R.S.; DAL PIAZ, G.V.; DEL MORO, A.; POTTS, P.J. 1984. Petrogenesis of calc-alkaline, shoshinitic and associated ultrapotassic Oligocene volcanic rocks from the Northwestern Alps, Italy. Contr. Miner. Petrol., 86:209-220.
WINCHESTER, J.A. \& FLOYD, P.A. 1977. Geochemical discrimination of different magma series and their differentiation products using imobile elements. Chem. Geol, 20:325-343.

WINDLEY, B.F. 1984. The evolving continents. New York, Wiley \& Sons. $339 \mathrm{p}$.

WIRTH, K.R. 1986. The geology and geochemistry of the Grão-Pará Group, Serra dos Carajás, Pará, Brazil. Cornell. 284 p. (M. Sc. Thesis, University of Cornell, Ithacal).

WIRTH, K.R.; GIBBS, A.K.; OLSZEWSKI, W.J., Jr. 1986. U-Pb ages of zircons from the Grão-Pará Group and Serra dos Carajás Granite, Pará, Brazil. Rev. Bras. Geoc., 16(2): 195-200

WOOD, D.A.; JORON, J.L.; TREUIL, M. 1979. A re-appraisal of the use of trace elements to classify and discriminate between magma series erupted in different tectonic setting. Earth Planet. Sci. Lett., 45:326-336.

MANUSCRITO A623 Recebido em 4 de outubro de 1989 Revisão do autor em 27 de julho de 1990 Revisão aceita em 31 de julho de 1990 